\title{
CARACTERIZACIÓN DE LA ENFERMEDAD RESPIRATORIA BAJA EN PACIENTES MENORES DE 5 AÑOS, HOSPITALIZADOS EN UN CENTRO DE $3^{\circ}$ NIVEL
}

\author{
JUAN LÓPEZ P', GLORIA GALÁN G1, DIOCEL LANCHEROS D ${ }^{1}$, \\ NARDA OLARTE E ${ }^{2}$, ALBERTO VALDERRAMA $M^{3}$. \\ ${ }^{1}$ Pediatras Hospital El Tunal, ${ }^{2}$ Médica epidemióloga, grupo de epidemiología Hospital El Tunal, \\ ${ }^{3}$ Enfermero Jefe, grupo de epidemiología Hospital El Tunal. \\ Hospital El Tunal ESE III nivel, Bogotá D.C. Colombia. Carrera 20 47B 35 sur. \\ Correspondencia: juanj.lopezp26@yahoo.es.
}

Recibido: 18 Enero 2016 Aceptado: 5 Julio 2016

\section{RESUMEN}

Introducción: Caracterizar la enfermedad respiratoria baja en pacientes hospitalizados basados en el panel viral, como parte del programa de vigilancia epidemiológica en Bogotá, Colombia.

Población y métodos: Trabajo retrospectivo transversal entre enero de 2010 y junio de 2011 en un hospital de tercer nivel, involucrando menores de 5 años, mediante inmunofluorescencia indirecta en aspirado nasofaríngeo para virus sincitial respiratorio (VSR), parainfluenza 1, 2, 3, influenza A, B y adenovirus.

Resultados: Se obtuvieron 1063 casos, encontrándose un mayor número en el primer semestre del segundo año (145\%). Los meses de mayor afectación fueron abril y mayo, siendo los hombres los más afectados. El promedio de edad fue de 8,18 meses; los menores de 1 año representaron el 75\% de los casos y los menores de 2 años el 93\%. En el $67 \%$ de los eventos no se aisló ninguno de los virus estudiados y en el $28 \%$ el VSR. El promedio de estancia hospitalaria fue de 7,11 días, siendo mayor para el VSR que para los otros virus o resultado negativo. El 51\% recibió antibióticos.

Conclusiones: Resultados similares a los descritos en la literatura pero analizados a la altura de Bogotá y en una comunidad de condición socioeconómica baja.

Palabras clave: Infección respiratoria baja, Panel viral, Inmunofluorescencia, Virus sincitial respiratorio. 


\title{
CHARACTERIZATION OF LOW RESPIRATORY DISEASE IN PATIENTS UNDER 5 YEARS OLD, HOSPITALIZED IN A CENTER OF $3^{\circ}$ LEVEL
}

\begin{abstract}
Introduction: Characterization of lower respiratory disease in hospitalized patients based on the viral panel as part of epidemiological surveillance program in Bogota, Colombia.

Population and methods: Transversal retrospective study between January 2010 and June 2011 from a tertiary level hospital was developed with children younger than 5 years old. Indirect immunofluorescence in nasopharyngeal aspirate for respiratory syncytial virus (RSV), parainfluenza 1, 2, 3; influenza A, B and adenoviruses were analyzed.

Results: 1063 cases were obtained, finding a greater number of cases in the first half of year (145\%). The months with higher affectation were April and May, men being the most affected. The average age was 8.18 months; children under 1 year old accounted for $75 \%$ of cases and children under 2 years old $93 \%$. In $67 \%$ of the events none of the studied virus was isolated and in $28 \%$ RSV. The average hospital stay was 7.11 days, being greater for RSV than for other viruses or negative. $51 \%$ received antibiotics.
\end{abstract}

Conclusion: The results were similar to those described in the literature but analyzed at the height of Bogota and in a community of low socio-economic status.

Keywords: Respiratory tract infections, Viral panel, Respiratory syncytial virus, Assay immunofluorescence.

\section{CARACTERIZAÇÃO DA DOENÇA RESPIRATÓRIA BAIXA EM PACIENTES MENORES DE 5 ANOS, HOSPITALIZADOS EM CENTRO DE 3 NÍVEIS}

\section{RESUMO}

Introdução: Caracterização da doença respiratória inferior em pacientes hospitalizados com base no painel viral como parte do programa de vigilância epidemiológica em Bogotá, Colômbia.

População e métodos: Estudo transversal retrospectivo entre jeiro de 2010 e junho de 2011 de um hospital de nível terciário foi desenvolvido com crianças menores de 5 anos. Imunofluorescência indireta em aspirado nasofaríngeo para o vírus respiratório sincitial (VSR), parainfluenza 1, 2, 3; Influenza A, B e adenovírus foram analisados.

Resultados: Foram obtidos 1063 casos, encontrando-se um maior número de casos na primeira metade do ano (145\%). Os meses com maior afetação foram abril e maio, sendo os homens os mais afetados. A média de idade foi de 8,18 meses; Crianças menores de 1 ano representaram 75\% dos casos e crianças menores de 2 anos 93\%. Em $67 \%$ dos eventos nenhum dos vírus estudados foi isolado e em $28 \%$ RSV. A média de internação hospitalar foi de 7,11 dias, sendo maior para RSV do que para outros vírus ou negativos. $51 \%$ receberam antibióticos.

Conclusão: Os resultados foram semelhantes aos descritos na literatura, mas analisados na altura de Bogotá e em uma comunidade de baixo status socioeconômico.

Palavras-chave: Infecções do trato respiratório, Painel viral, Virus sincicial respiratório, Imunofluorescência de ensaio. 


\section{Introducción}

La infección respiratoria aguda baja (IRAB) en menores de 5 años es la primera causa de morbimortalidad a nivel mundial (1). La Organización Mundial de la Salud (OMS) estima que la tercera parte de los fallecimientos son causados por IRAB, fundamentalmente por neumonía, constituyéndose en una importante causa de morbimortalidad en América Latina (2,3). En las Américas cada año mueren alrededor de 140.000 a 150.000 niños menores de cinco años por IRAB, de ellos 100.000 son menores de un año y 40.000 a 50.000 de uno a cuatro años de edad (3), ocasionadas el $90 \%$ por neumonía (4).

En nuestra institución la IRAB en niños y niñas hasta los 5 años de edad constituye una de las primeras causas de consulta de urgencias y hospitalización. En este trabajo caracterizamos variables demográficas, etiológicas, duración hospitalaria, uso de antibióticos y condición al egreso de los pacientes atendidos en el servicio de pediatría de una institución hospitalaria de tercer nivel, a una altura de 2.650 metros sobre el nivel del mar (m.s.n.m.), con el objetivo de generar información que pueda ser utilizada en la prevención de la enfermedad y en la planeación de los servicios de atención de la población pediátrica.

\section{Población}

El Hospital El Tunal E.S.E Nivel III, es una institución hospitalaria que pertenece a la Red Pública de Hospitales de la ciudad de Bogotá (a 2.650 m.s.n.m.), Colombia, contando con 33 camas de pediatría.

Desde el año 2007 la institución inició la participación en la vigilancia centinela de Enfermedad Respiratoria similar a Influenza, que tiene como criterios epidemiológicos: aparición súbita de fiebre superior a $38^{\circ} \mathrm{C}$, tos o dolor de garganta, dificultad para respirar (disnea), necesidad de hospitalización y un máximo de 7 días de evolución. La población estudio correspondió a los niños menores de 5 años con enfermedad respiratoria aguda hospitalizados entre el 1 de enero de 2010 y el 30 de junio de 2011.

\section{Métodos}

A los pacientes que cumplían con los requisitos expuestos se procedió a tomar muestras de aspirado nasofaríngeo para la realización de panel viral, mediante el apoyo de terapistas respiratorias entrenadas. En una jeringa se mezcla el contenido del kit que contiene anticuerpos monoclonales para los 7 virus de interés, además de un estabilizador (azul de Evans) y preservante. Estando el paciente en ayuno se introduce una sonda conectada a la jeringa a través de la nariz procediendo a realizar aspiración con el fin de obtener un volumen de secreciones nasofaríngeas de $1 \mathrm{ml}$. El contenido total de la muestra se distribuye en 2 frascos que se embalan, anotando la fecha y hora de la toma, nombre del paciente y número de historia clínica, enviándose inmediatamente al laboratorio. Si el volumen del líquido no era suficiente, el procedimiento era repetido. En el laboratorio, bacteriólogas de la institución, quienes ya habían recibido instrucción en el manejo y procesamiento de las muestras, utilizando procedimientos estándar y controles de calidad, emplearon técnicas de inmunofluorescencia indirecta para la identificación de 7 virus (sincitial respiratorio, influenza A y B, adenovirus, parainfluenza 1, 2 y 3), manejando el reactivo Light Diagnostics ${ }^{\text {TM }}$ Respiratory Panel 1 viral Screening (5). Concomitantemente, se le realizó una prueba rápida para el virus sincitial respiratorio (VSR): RapidSignal RSV dipstrip, test inmunocromatrográfico cualitativo que utiliza anticuerpos monoclonales.

A partir de la realización del panel viral, la búsqueda de casos se efectuó en dos bases de datos: laboratorio clínico y epidemiología. A continuación se revisaron las historias clínicas por personal médico en formación previamente entrenado, bajo el seguimiento del grupo de investigadores, recolectando los datos en una hoja cálculo de Excel con las siguientes variables: fechas ingreso-egreso, edad de ingreso, género, resultado del panel viral y de la prueba rápida para el VSR, uso de antibióticos, duración de la hospitalización, destino final (casa - con o sin oxígeno domiciliario - remisión, fallecimiento). Se excluyó un caso por deficiencias en el registro.

El estudio fue aprobado por el Comité Ética de Investigaciones del Hospital El Tunal el 8 de febrero de 2012.

\section{Análisis estadístico}

El análisis univariado se presenta como frecuencias para las variables nominales y con medias o medianas (con su desviación estándar o rango intercuartílico según corresponda) para las variables cuantitativas, según éstas sigan o no distribución normal respectivamente. Para su cálculo nos valimos de la hoja dinámica Excel de Microsoft. Las asociaciones bivariadas se obtuvieron con el paquete estadístico Stata, mediante la prueba Chi-cuadrado para las variables nominales, y Mann Whitney o Kruskal Wallis, cuando se consideró como variable dependiente a la estancia hospitalaria. 


\section{Resultados}

Se obtuvieron 1063 casos de 988 pacientes. De ellos, 925 (93\%) se hospitalizaron en una ocasión, 53 (5\%) en dos, $8(0,8 \%)$ en tres y $2(0,2 \%)$ en cuatro.
En la tabla 1 se aprecian las características clínicas, demográficas y terapéuticas de los casos estudiados en general y según el resultado del panel viral. El predominio masculino prevaleció hasta los 2 años (564 hombres versus 437 mujeres), para luego predominar en las mujeres (29 hombres y 33 mujeres).

Tabla 1. Características clínicas y demográficas del total de casos y según el resultado del panel viral

\begin{tabular}{|c|c|c|c|c|c|}
\hline & & Global & Panel negativo & Panel positivo & $\mathbf{P}^{*}$ \\
\hline$n(\%)$ & & $1063(100)$ & $720(67,73)$ & $343(32,27)$ & \\
\hline Sexo masculino, n(\%) & & $593(55,8)$ & $413(57,36)$ & $180(52,48)$ & 0,134 \\
\hline \multirow{4}{*}{$\begin{array}{l}\text { Grupo etario en meses } \\
\text { cumplidos, } n(\%)\end{array}$} & $<6$ & $541(50,9)$ & $368(51,1)$ & $173(50,4)$ & \multirow{4}{*}{0,37} \\
\hline & Entre 6 y 11 & $256(24,1)$ & $167(23,2)$ & $89(26)$ & \\
\hline & Entre 12 y 23 & $196(18,4)$ & $141(19,6)$ & $55(16)$ & \\
\hline & 24 o más & $70(6,6)$ & $44(6,1)$ & $26(7,6)$ & \\
\hline Recibió antibiótico & n (\%) & $544(51,2)$ & $355(49,3)$ & $189(55,1)$ & 0,077 \\
\hline O2 domiciliario & $\mathrm{n}(\%)$ & $312(29,5)$ & $207(28,9)$ & $105(30,7)$ & 0,55 \\
\hline \multirow{4}{*}{ Edad (meses) } & & Mediana $(\mathrm{RIC})^{* * *}$ & Mediana (RIC) & Mediana (RIC) & 0,625 \\
\hline & Total: & $5(2-12)$ & $5(2-12)$ & $5(2-11)$ & \\
\hline & Hombres: & $6(2-12)$ & $6(2-13)$ & $5,5(2-11)$ & 0,862 \\
\hline & Mujeres: & $5(2-11)$ & $5(2-11)$ & $5(2-12)$ & 0,356 \\
\hline \multirow{7}{*}{ Estancia } & Total: & $6(3-9)$ & $6(3-8)$ & $7(5-9)$ & $<0,001$ \\
\hline & Hombres: & $6(3-9)$ & $6(3-9)$ & $7(5-9)$ & 0,0003 \\
\hline & Mujeres: & $6(3-9)$ & $5(3-8)$ & $7(5-10)$ & $<0,001$ \\
\hline & $<6 \mathrm{~m}(\mathrm{n}=541)$ & $7(4-9,5)$ & $6(3-9)$ & $8(5-10)$ & $<0,001$ \\
\hline & $6-11 m(n=256)$ & $6(3-9)$ & $6(3-8)$ & $7(4-9)$ & 0,04 \\
\hline & $12-23 m(n=196)$ & $5(3-7,8)$ & $5(2-7,5)$ & $6(5-8)$ & 0,02 \\
\hline & $>23 m(n=70)$ & $6(4-7)$ & $4,5(4-6,8)$ & $6(4,8-8)$ & 0,058 \\
\hline
\end{tabular}

* Valores de p para el contraste de distribución de las diferentes variables entre el grupo del panel viral positivo, comparado con el panel viral negativo.

** RIC: Rango intercuartil. 
Tabla 2. Frecuencia de virus identificados y sus asociaciones

\begin{tabular}{l|c|c|c|c}
\hline Resultado del panel & Masculino & Femenino & Total & $\mathbf{\%}$ \\
\hline Negativo & 413 & 307 & 720 & $67,73 \%$ \\
\hline VSR & 154 & 127 & 281 & $26,43 \%$ \\
\hline Parainfluenza 3 & 7 & 9 & 16 & $1,51 \%$ \\
\hline Parainfluenza 3 + VSR & 7 & 6 & 13 & $1,22 \%$ \\
\hline Influenza B & 3 & 4 & 7 & $0,66 \%$ \\
\hline Parainfluenza 1 & 3 & 4 & 7 & $0,66 \%$ \\
\hline Influenza B + VSR & 1 & 5 & 6 & $0,56 \%$ \\
\hline Adenovirus + VSR & 1 & 4 & 5 & $0,47 \%$ \\
\hline Adenovirus & 1 & 2 & 3 & $0,28 \%$ \\
\hline Parainfluenza 2 & 2 & 1 & 3 & $0,28 \%$ \\
\hline Parainfluenza 1 + VSR & 1 & 1 & 2 & $0,19 \%$ \\
\hline Total & $\mathbf{5 9 3}$ & $\mathbf{4 7 0}$ & $\mathbf{1 0 6 3}$ & $\mathbf{1 0 0 , 0 0 \%}$ \\
\hline
\end{tabular}

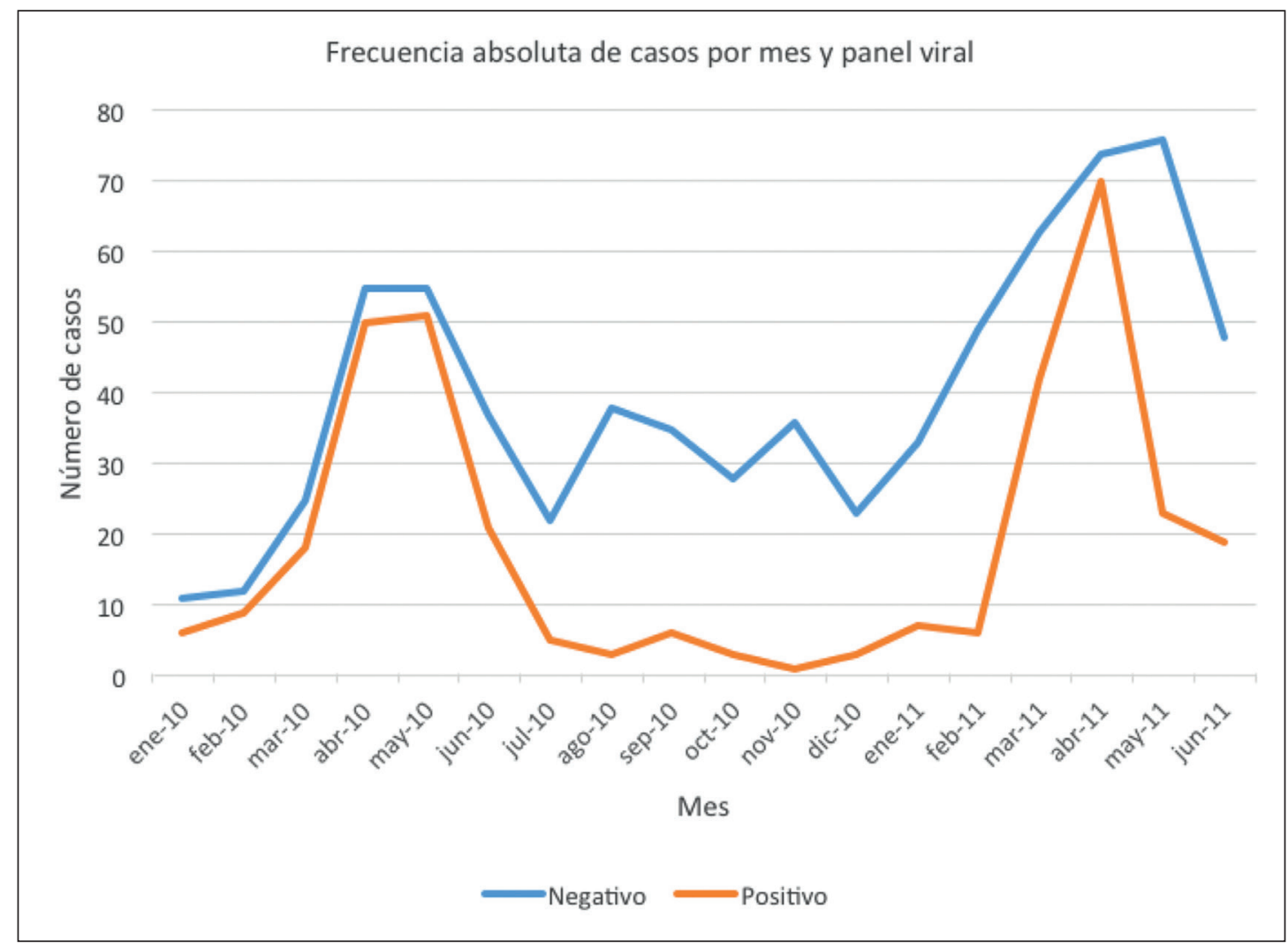

Gráfico 1. Número de Casos por mes de ingreso, según el panel viral. n=1063 
También el predominio fue masculino en los hospitalizados en más de una ocasión (57\%) y cuando se aíslo el VSR; no así en los aislamientos de virus diferentes al VSR, solos o en coinfección con este, donde la mayor frecuencia se presentó en el sexo femenino (20 vs 16, relación $1,25: 1$ y 36 versus 26 , relación $1,38: 1$, respectivamente).

Para el panel viral negativo como el positivo, o sus asociaciones, su mayor frecuencia coincidió en la misma época (Gráfica 1).

Los más afectados fueron los menores de 6 meses (especialmente de 1 y 2 meses), tanto para el género masculino como el femenino (294 y 247 casos respectivamente), representando el $51 \%$ de los casos; los menores de un año correspondieron al $75 \%$ y los menores de 2 años al 93\%.

De los que se hospitalizaron en más de una ocasión, el promedio de edad en su primera hospitalización fue de 5,3 meses (IC 3,8-6,8), siendo el 57\% menor de 3 meses y $90 \%$ menor de 1 año. Los que se hospitalizaron solo 2 veces, la edad promedio de su primera hospitalización fue de 5,7 meses (IC 3,9-7,47) y cuando se hospitalizaron en 3 ocasiones fue de 3,3 meses (IC 2,0-4,71).

La edad promedio para los afectados de otros virus diferentes al VSR fue de 10,08 meses (IC 7,4-12,75), siendo en las mujeres de 9,7 (IC 6,6-12,8) y en los hombres de 10,58 (IC 5,75-15,4).

La frecuencia de negatividad del panel viral fue muy similar en las distintas edades: en menores de 6 meses $68 \%$, entre los 6 y 12 meses $64 \%$, entre los 12 y 18 meses $72 \%$, entre los 18 y 24 meses $71 \%$ y en los mayores de 24 meses $62 \%$.

Cuando se hospitalizaron en más de una ocasión, continuó predominando el panel viral negativo ( $72 \%$ con 2 ingresos, $83 \%$ con 3 y $87 \%$ con 4$)$, seguido por el VSR $(20 \%$, $16 \%$ y $12 \%$ para 2,3 y 4 ingresos respectivamente).

Se utilizaron antibióticos así: en el 51\% de los hombres, en el 51\% (189/343) de los niños con panel viral positivo, en el 49\% (355/720) de los casos con panel negativo y en el $53 \%$ de quienes se les identificó más de un virus. En los menores de 6 meses el $42 \%$ los recibió, entre 6 a 11 meses el 59\%, entre 12 a 23 meses el $67 \%$ y de 24 o más meses el $55 \%$.
En el análisis bivariado, se encontró que la estancia hospitalaria fue significativamente mayor cuando se identificó algún virus ( 7 contra 6 días), en los periodos de mayor incidencia (6 contra 5 días) y cuando se usaron antibióticos (7 contra 5). Si se utilizaron antibióticos, el resultado del panel viral no se asoció con diferencias en la estancia; tampoco se demostró diferencia según el número de ingresos (Tabla 3).

Egresaron con oxígeno domiciliario 312 (29\%), con un promedio de edad de 4,4 meses (IC 3.91-4.97), comparado con 10,1 meses (IC 9,48-10.86) de los que no lo requirieron. El 73\% eran menores de 6 meses, el $18 \%$ entre 6 a 11 meses, el 6\% entre 12 a 23 meses y el $0,99 \%$ de 24 meses o más. De los menores de 6 meses el $46 \%$ egresó con oxígeno domiciliario, de 6 a 11 meses el 25\%, de 12 a 23 meses el 6\% y de 24 o más meses el $4 \%$. De los que no recibieron antibióticos el $29 \%$ lo requirió, comparado con el $66 \%$ de los que recibieron antibióticos. El 31\% de las mujeres y el 32\% hombres salieron con oxígeno domiciliario. El $32 \%$ de los casos VSR positivo y el $31 \%$ de los VSR negativos egresaron con oxígeno domiciliario. La presencia de más de un virus no cambió tal proporción.

963 casos (90\%) egresaron a su casa, 90 (8\%) se remitió a otras instituciones y $10(0,94 \%)$ fallecieron. Entre los 10 fallecidos el rango de edad fue de 0 a 32 meses (media de 6,4), 4 eran hombres, en 4 se asilaron virus (3 VSR y en uno adenovirus) y a 9 se les administró antibióticos. Su promedio de estancia hospitalaria fue de 13,9 días (rango 2 a 62), ocurriendo 3 casos en abril de 2011.

\section{Discusión}

La IRAB en menores de 5 años a nivel mundial sigue siendo una de las causas de mayor morbimortalidad (1). En nuestra institución también constituye la causa más frecuente de egreso hospitalario y su incidencia sigue el mismo patrón observado en la ciudad, con un primer pico entre marzo y junio $(5,6)$, meses caracterizados por ser más fríos y húmedos, lo que facilita el hacinamiento (7) y la diseminación domiciliaria de los virus. Este mayor contagio probablemente esté también relacionado con el ingreso de los niños a guarderías y colegios. Los cambios relacionados con la circulación de los diferentes genotipos pueden generar variabilidad en la incidencia y gravedad de la IRAB (8), lo cual podría explicar el aumento del número de casos detectados en el primer semestre del 2011 con respecto al 2010. En Bogotá el pico epidémico ocurre en épocas de lluvias, principalmente en los meses de abril y mayo, 
Tabla 3. Estancia hospitalaria

\begin{tabular}{|c|c|c|c|}
\hline Variable & $\begin{array}{l}\text { Total de casos } \\
\qquad \mathrm{n}=1063\end{array}$ & $\begin{array}{l}\text { Mediana en } \\
\text { número de días } \\
\text { (RIC) }\end{array}$ & $\mathbf{p}^{*}$ \\
\hline VSR Positivo & 307 & $7(5-9)$ & \multirow{2}{*}{$<0,0001$} \\
\hline VSR Negativo & 756 & $6(3-8)$ & \\
\hline Otros virus con o sin VSR & 62 & $6(4-8)$ & \multirow{4}{*}{$<0,001$} \\
\hline VSR solo & 281 & $7(5-9)$ & \\
\hline Virus diferentes a VSR & 36 & $6(4-8)$ & \\
\hline Panel negativo & 720 & $6(3-8)$ & \\
\hline Meses de mayor circulación & 727 & $6(4-9)$ & \multirow{2}{*}{$<0,001$} \\
\hline Meses de menor circulación & 336 & $5(2-8)$ & \\
\hline \multirow{2}{*}{$\begin{array}{l}\text { Se usaron antibióticos } \\
\text { No se usaron antibióticos }\end{array}$} & 544 & $7(5-10)$ & \multirow{2}{*}{$<0,0001$} \\
\hline & 519 & $5(2-7)$ & \\
\hline \multirow{2}{*}{$\begin{array}{l}\text { Panel negativo y uso de antibióticos } \\
\text { Panel negativo sin uso de antibióticos }\end{array}$} & 355 & $7(4-10)$ & \multirow{2}{*}{$<0,0001$} \\
\hline & 365 & $4(2-6)$ & \\
\hline \multirow{2}{*}{$\begin{array}{l}\text { Panel positivo y uso de antibióticos } \\
\text { Panel positivo sin uso de antibióticos }\end{array}$} & 189 & $8(6-10)$ & \multirow{2}{*}{0,0001} \\
\hline & 154 & $6(4-8)$ & \\
\hline \multirow{2}{*}{$\begin{array}{l}\text { Sin antibiótico panel positivo } \\
\text { Sin antibiótico panel negativo }\end{array}$} & 154 & $6(4-8)$ & \multirow{2}{*}{$<0,0001$} \\
\hline & 365 & $4(2-6)$ & \\
\hline \multirow{2}{*}{$\begin{array}{l}\text { Con antibiótico panel positivo } \\
\text { Con antibiótico panel negativo }\end{array}$} & 189 & $8(6-10)$ & \multirow{2}{*}{0,2096} \\
\hline & 355 & $7(4-10)$ & \\
\hline Primer ingreso & 988 & $6(3-9)$ & \\
\hline Segundo ingreso & 63 & $6(2-8)$ & \\
\hline Tercer ingreso & 10 & $7,5(4-9)$ & \\
\hline Cuarto ingreso & 2 & $9,5(7-12)$ & $p=0,55$ \\
\hline
\end{tabular}

* Valor de p para los contrastes de diferencia de la estancia hospitalaria según las variables descritas. 
no coincidiendo con el hemisferio norte o sur ni con lo descrito en otras zonas ecuatoriales del mundo (9). En otras latitudes, las tasas mensuales de infección por VRS se han correlacionado negativamente con la temperatura media mensual, sol total, precipitación, humedad relativa y la velocidad media del viento (10).

De manera global, los hombres se afectan más que las mujeres $(11,12)$, proporción que también se evidenció en nuestro estudio y que se mantuvo cuando los pacientes fueron hospitalizados en más de una ocasión. Sin embargo, a partir de los dos años, hubo un predominio del sexo femenino, lo cual también se observó cuando el causante de la IRAB fue un virus diferente al VSR.

En concordancia con Jain S y cols, encontramos que los menores de dos años fueron los más afectados, especialmente los menores de un año (13). El género o el panel viral negativo no influyó en la edad promedio; sin embargo, la edad de presentación sí fue mayor cuando el panel viral fue positivo para otros virus diferentes al VSR o cuando se asociaron con él, especialmente en el sexo masculino $(p=0,043)$, datos que coinciden con lo reportado por Sardón Prado y col, Gereige RS y cols y Mei-Ping Lu y col $(14,15,16)$. En los pacientes que se hospitalizaron en más de una ocasión, pareciera que el hecho de presentar un primer episodio a edades más tempranas constituyera un factor de riesgo para su recurrencia.

El panel viral negativo fue el resultado más frecuente, aislándose algún virus en el $32 \%$ de los casos, aunque se sabe que con un amplio panel de pruebas se puede llegar a establecer la etiología de la IRAB en cerca del 85\% (7). Coincidiendo con lo descrito por Øymar K y Fox TG $(17,18)$, predominó en el panel positivo el VSR (89\%), seguido del parainfluenza (11\%). En Colombia, Piñeros JG y cols. reportaron que en la IRAB el VSR representó el 30\% de los casos y a nivel de Bogotá el 26\% (12), muy similar a lo que encontramos: $28 \%$. Algunos reportan coinfecciones virales con el VSR del $32 \%$ (19), mayor a la nuestra, pero hay que tener en cuenta los métodos diagnósticos que utilizamos y la búsqueda de solo 7 virus. No encontramos asociaciones entre los virus de menor frecuencia.

Se esperaría que a mayor edad el panel viral negativo sería más frecuente, pero esto no lo observamos. En cambio, a mayor número de hospitalizaciones el porcentaje de aislamiento viral fue menor, siendo el VSR el más frecuentemente hallado.

En uso de antibióticos sobrepasó el 50\%, siendo mayor al aumentar la edad, tal vez asociado al hecho de que los virus predominan en los menores (13), siendo menor su utilización (20). La presencia de más de un virus aumentó el uso de antibióticos. En las neumonías adquiridas en comunidad (NAC) la literatura reporta infecciones mixtas (bacterianas y virales) en el 23 al 33\% de los casos (21), junto a la dificultad para diferenciar la neumonía viral de la bacteriana $(7,15,22)$ y la posibilidad de que la IRAB sea bacteriana es mayor en los países en vías de desarrollo (23), constituyen factores que inciden en el uso de antibióticos. Un metaanálisis sobre el VSR hecho en América Latina mostró que alrededor del $50 \%$ de los niños sin comorbilidades, menores de 59 meses, reciben antibióticos (25). Jain S y col reportan en un estudio reciente que a pesar de solo encontrar etiología bacteriana en el 15\% de las NAC, se utilizaron antibióticos en el $88 \%$ de los casos (13). Igualmente, Kenneth Escobar y col encontraron que el $81 \%$ de los positivos para un virus respiratorio recibieron antibióti$\cos (24)$. Aunque nuestra institución cuenta con guías para el manejo de bronquiolitis y NAC, el uso de antibióticos depende generalmente de la apreciación clínica que hace al ingreso el pediatra en conjunto con una radiografía de tórax, un cuadro hemático y la proteína $\mathrm{C}$ reactiva. Por ser una institución de tercer nivel que cuenta con unidad de cuidados intensivos pediátricos, con frecuencia recibe pacientes graves de otras instituciones, lo que hace aumentar el uso de los mismos.

Dentro de los factores que incidieron en la estancia hospitalaria están la edad (a menor edad mayor es esta, $\mathrm{p}<$ 0,01 ), la época del año (en los meses de mayor incidencia esta se prolonga, $p=0,0035)$, el aislamiento viral (el VSR la prolonga, $p=0,0029$ ), el uso de antibióticos (estos prolongan la hospitalización, $p<0,001$ ), el primer episodio, pudiendo interpretarse como causas de una mayor severidad del cuadro clínico. La necesidad de oxigeno domiciliario también prolongó la estancia hospitalaria $(p<0,001)$, pero habría que interpretarlo con cautela ya que los trámites administrativos pueden influir en estos resultados. Dentro de los factores de gravedad en la NAC se han enunciado la saturación de oxígeno al ingreso, la dificultad respiratoria, la duración de la estancia hospitalaria (15), la carga viral (26), la respuesta inmune (27) y la base genética (28). Un metaanálisis encontró que para el VSR, en América Latina, el promedio de estancia hospitalaria, excluyendo los ingresados a UCI y sin factores de riesgo, fue de 7,3 días en la edad de 0 a 11 meses (recibiendo antibióticos el 60,7\%), de 7,6 días entre los 0 a 23 meses (recibiendo antibióticos el 33,3\%) y de 6,3 días entre los 0 a 59 meses (recibiendo antibióticos el 53\%) (25). Estos datos son muy similares a los encontrados por nosotros. Para la NAC la 
duración promedio de hospitalización en Latinoamérica es de 11 días (29), aunque en Estados Unidos es de 3 días (13). Entre los factores que inciden en los altos costos de hospitalización están la duración de la hospitalización y el uso inadecuado de los antibióticos (29).

Se encontró que el $28 \%$ de los pacientes requirió oxígeno domiciliario, constituyendo el factor condicionante la edad (a menor edad mayor es su solicitud), mas no el tipo de virus, la coinfección viral, el género o el uso de antibióticos.

La mortalidad fue del 0,94\%, (aunque se desconoce la evolución final de los pacientes que se remitieron a otras instituciones), siendo mayor en las mujeres, en los de menor edad y cuando el panel viral fue negativo, siendo los dos últimos datos concordantes con los grupos más afectados. Igualmente, el VSR fue el virus más aislado. Se describe que, dentro de los factores de riesgo para fallecer, sin tener en cuenta las comorbilidades, están la edad menor de 6 meses, la presencia del VSR con adenovirus (30) y los meses de mayor incidencia (12), datos que concuerdan con nuestro trabajo.

Dentro de las fortalezas del trabajo se evidenciaron haber involucrado a todos los pacientes que cumplian con los criterios de ingreso hasta la edad de 5 años con enfermedad respiratoria, con solo un caso perdido; se llevó un registro durante 18 meses para ver la evolución en el tiempo, todos tuvieron el estudio del panel viral. Es de resaltar que el trabajo se realizó en niños de estrato socioeconómico bajo que viven por encima de 2500 msnm.

Dentro de las debilidades podemos anotar que por tratarse de un trabajo retrospectivo transversal presenta las limitaciones propias de este tipo de estudios, además la falta de estandarización en el manejo de los pacientes (especialmente en lo relacionado con el uso de antibióticos y el momento de solicitud de oxígeno domiciliario), los métodos diagnósticos utilizados en la identificación viral y la búsqueda de solo 7 virus.

\section{Conclusiones}

Se hizo una caracterización de la infección respiratoria en una institución de III nivel que maneja estratos socioeconómicos bajos y a la altura de Bogotá. El método de diagnóstico que utilizamos (inmunofluorescencia indirecta) buscó 7 virus respiratorios, observándose que en el grupo más grande de pacientes no se detectó ningún virus, lo que obliga a realizar este tipo de estudios utilizando la reacción en cadena de la polimerasa (PCR), que ha mostrado un mejor rendimiento y con paneles más amplios que cubran, además de los virus anotados, otros que se vienen describiendo con cada vez más frecuentemente (rinovirus, metapneumovirus, bocaneumovirus, etc.). De los virus aislados, el más frecuente, en gran manera, fue el VSR. La IRAB predominó en los niños menores, los varones y la primera mitad del año. Cuanto menor es la edad de presentación del primer evento mayor es el riesgo de recurrencia. Todo lo anterior obliga a insistir en las medidas preventivas para evitar el contagio ya sea en la casa o en las instituciones como guarderías o colegios. De manera global, el uso de antibióticos sobrepasó el $50 \%$ de los casos. Nuestras estancias hospitalarias son similares a las reportadas en algunos sitios de América Latina, pero más altas que en otras latitudes. Habría que pensar si se pueden aplicar en nuestro medio algunos de los puntajes que se describen en la literatura y que se utilizan para diferenciar neumonía viral de bacteriana, con parámetros clínicos, de laboratorio y radiológicos (31, 32). Un alto número de niños egresó con oxígeno domiciliario, lo cual pudo deberse a falta de estandarización en la toma de la pulsoximetría, la severidad de la enfermedad o la elevada altura sobre el nivel del mar. Nuestra mortalidad es similar a la de otros estudios.

Por último, estos resultados buscan servir para la toma de medidas de choque correspondientes, ampliar la búsqueda etiológica del panel viral negativo y racionalizar el uso de antibióticos, entre otras. Se requieren estudios prospectivos donde se evalúen en nuestras comunidades parámetros clínicos y paraclínicos que ayuden a diferenciar la IRAB viral y bacteriana.

\section{Conflictos de interés}

Los autores del trabajo declaran no tener ningún conflicto de interés.

\section{Financiación}

El panel viral fue aportado por Secretaria Distrital de Salud de Bogotá y no contó con financiación adicional.

\section{Agradecimientos}

Los autores expresamos nuestro agradecimiento al personal del Hospital el Tunal que colaboró en la realización de este trabajo, pero muy especialmente a las Dras. María Lucia Cock Genney, Doris Consuelo Vargas y Jennifer Moreno Villamizar, cuya participación fue muy relevante, especialmente en la recolección de la información, base fundamental para el ulterior desarrollo del mismo. 


\section{Referencias}

1. Saenz David J, Vergara Caly K, Zambrano Quintero M et al. Incidencia de neumonía diagnosticada radiologicamente en bronquiolitis moderada a severa en niños de una comunidad pobre, hospitalizados en el Hospital Infantil Napoleón Franco Pareja. Enero a Mayo 2009. Sociedad Chilena de Neumología Pediatrica. Neumología Pediatrica 2010;supl. 1:1-93.

2. Guía Clínica de Infección Respiratoria Aguda Baja de manejo Ambulatorio en menores de 5 años. Ministerio de salud. 1st Ed. Santiago: Minsal. 2005.

3. Tamayo Peña DI, Almarales Sarmiento G, Pupo Damas H, Tamayo Serrano JR. Infecciones respiratorias agudas bajas en menores de cinco años de Hatu-Builico, Leste Timor. Correo Científico Médico de Holguín 2008;12(4).

4. Instituto Nacional de Salud. vigilancia y análisis del riesgo en salud pública protocolo de vigilancia en salud pública infeccion respiratoria aguda (IRA). PRO-RO2.010. versión 03. 11-Junio-2014.

5. Light diagnostics ${ }^{\mathrm{TM}}$ Respiratory Panel 1 DFA Para la identificación de Adenovirus, Influenza A, Influenza B, Parainfluenza 1, Parainfluenza 2, Parainfluenza 3 y VRS Cat. No. 3110 Suplemento Español De la Lengua Para Diagnóstico In Vitro.

6. Instituto Nacional de Salud. Boletín Epidemiológico Semanal. Semana epidemiológica número 41 de 2015 (11 oct. al 17 oct.).

7. Martín AA, Moreno Pérez D, Alfayate Miguelez S, Couceiro Gianzo JA et al. Etiología y diagnóstico de la neumonía adquirida en la comunidad y sus formas complicadas. An Pediatr (Bar). 2012; 76(3):162e1-162e18).

8. Morales O, Durango H y González Y. Etiología de las neumonías adquiridas en comunidad en la población infantil. Neumol Pediatr 2013; 8(2):53-65.

9. Ucrós S, Dueñas EM, Gutiérrez ML. Calendario y variación estacional de las afecciones respiratorias en la ciudad de Santa Fé de Bogotá. Rev Colomb Neumol. 1997; 9:124-32.

10. Xue-Lan Zhang, Xue-Jun Shao, Jian Wang, Wan-Liang Guo. Temporal characteristics of respiratory syncytial virus infection in children and its correlation with climatic factors at a public pediatric hospital in Suzhou. Journal of Clinical Virology 58-2013; 666- 670.

11. Hasegawa K, Mansbach JM, Teach SJ, Fisher ES, Hershey D, Kohm JY et al. Multicenter study of viral etiology and relapse in hospitalized children with bronchiolitis. $\mathrm{Pe}-$ diatr Infect Dis J. 2014;XX:00-00

12. Piñeros JG, Baquero H, Bastidas J, García J, Ovalle O, Patiño CM, Restrepo JC. Respiratory syncytial virus infection as a cause of hospitalization in population under 1 year in Colombia. J Pediatr (Rio J). 2013; 89(6):544-548.

13. Jain S, Williams DJ, Arnold SR, Ampofo K el at. Community-Acquired Pneumonia Requiring Hospitalization among U.S. Children. N Engl J Med 2015; 372:835-45.
14. Sardón Prado O, Corcuera Elosegui P, Korta Murua J y González Pérez-Yarza E. De la bronquiolitis al asma. Sibilancias en el lactante 2009. José Ramón Villa Asensi Editor. 2009. LUZÁN 5, S. A. de Ediciones.

15. Gereige RS and Marcelo Laufer P. Pneumonia. Pediatrics in Review 2013; 34;438.

16. Mei-Ping Lu, Li-Ya Ma, Qi Zheng, Li-Li Dong, Zhi-Min Chen. Clinical characteristics of adenovirus associated lower respiratory tract infection in children. World $\mathrm{J}$ Pediatr 2013; 9(4):346-349.

17. Øymar K, Ove Skjerven $H$ and Bruun Mikalsen I. Acute bronchiolitis in infants, a review. Scand J of Trauma, Resusc Emerg Med. 2014; 22:23.

18. Fox TG and Christenson JC. Influenza and Parainfluenza Viral Infections in Children. Pediatr Rev 2014; 35;217-28.

19. Mansbach JM, Piedra PA, Teach SJ, et al. Prospective multicenter study of viral etiology and hospital length of stay in children with severe bronchiolitis. Arch Pediatr Adolesc Med 2012; 166:700-706.

20. Ochoa Sangrador C, González de Dios J y Grupo de Revisión del Proyecto abreviado (Bronquiolitis-Estudio de Variabilidad, Idoneidad y Adecuación). Conferencia de Consenso sobre bronquiolitis aguda (II): epidemiologra de la bronquiolitis aguda. Revisión de la evidencia científica. An Pediatr (Barc). 2010; 72(3):222.e1-222.e26.

21. Iroh Tam PY. Approach to common bacterial infections: Community-Adquired Pneumonia. Pediatr Clin N Am. 2013:1-17.

22. Libia L. Diagnóstico de neumonía adquirida en la comunidad en la población infantil. Neumol Pediatr. 2013; 8(2):66-73.

23. Ucrós Rodríguez S. Neumonía adquirida en la comunidad. [aut. libro] Natalia Mejía Gaviria Santiago Ucrós Rodríguez. Guías de Pediatría Práctica basadas en la evidencia. 2. s.l. : Editorial Médica Panamericana, 2009, págs. 187-203.

24. Kenneth Escobar K, Chávez M, López C, Mejía M, Moscoso F. Tendencia terapéutica en neumonía adquirida en la comunidad de origen viral en niños menores de 2 años. Neumol Pediátr. 2010; 5(sup 1):13.

25. Bardach A, Rey-Ares L, Cafferata ML, Cormick G, Romano M, Ruvinsky S, et al. Systematic review and meta-analysis of respiratory syncytial virus infection epidemiology in Latin America. Rev. Med. Virol. 2014; 24: 76-89.

26. DeVincenzo JP, El Saleeby CM, Bush AJ. Respiratory syncytial virus load predicts disease severity in previously healthy infants. J Infect Dis 2005,191:1861-1868.

27. Mejías A, García C, Rodríguez R y Ramilo O. Virus respiratorio sincitial y otros virus en las sibilancias del lactante. Villa JR. Sibilancias en el lactante. Madrid. Luzán 5, S. A. de Ediciones.2009; p. 51-72.

28. Tapia L, Ampuero S, Palomino MA et al. Polimorfismos en genes de interleuquina (IL) 4 y receptores de IL-4 (IL4R) determinan gravedad por virus respiratorio sincitial y su evolución a largo plazo. Sociedad Chilena de Neumología Pediatrica (ed.). Neumología Pediatrica. 2010; 5:1-93. supl. 1.

29. Agudelo Vega B. Neumonía adquirida en la comunidad en 
pediatría: Latinoamérica. Neumol Pediatr. 2013; 8(2):51-2).

30. Rodríguez DA, Rodríguez-Martínez CE, Cárdenas AC, Quilaguy IE, Mayorga LY, Falla LM, Nino G. Predictors of severity and mortality in children hospitalized with respiratory syncytial virus infection in a tropical region. Pediatr Pulmonol. 2014; 49(3):269-76.

31. Agudelo Vega BI, Arango Loboguerrero M, Cala Vecino LL y cols. Guía de práctica clínica en el tratamiento del niño de un mes a diecisiete años con neumonía adquirida en la comunidad. [ed.] Asociación Colombiana de Neumología Pediátrica. 2010. Vol. Guía No. 5.
32. World Health Organization. Standardizacion of interpretation of chest radiographs for the diagnosis of pneumonia in children. TI, Group PV. Geneva. departament of vaccines and biologicals. 2001. 